\title{
Article \\ The Submarine Habitability Assessment Questionnaire: A Survey of RAN Submariners
}

\author{
Kate Ponton*, Dion Parera and Jessica Irons
}

Citation: Ponton, K.; Parera, D.;

Irons, J. The Submarine Habitability Assessment Questionnaire: A Survey of RAN Submariners. J. Mar. Sci. Eng. 2021, 9, 54. https://doi.org/ 10.3390/jmse 9010054

Received: 11 December 2020 Accepted: 29 December 2020 Published: 6 January 2021

Publisher's Note: MDPI stays neutral with regard to jurisdictional clai$\mathrm{ms}$ in published maps and institutional affiliations.

Copyright: $(\odot 2021$ by the authors. Licensee MDPI, Basel, Switzerland. This article is an open access article distributed under the terms and conditions of the Creative Commons Attribution (CC BY) license (https:// creativecommons.org/licenses/by/ $4.0 /)$.
Defence Science and Technology Group, Bldg A51, HMAS Stirling, Rockingham, WA 6168, Australia; dion.parera@gmail.com (D.P.); jessica.irons@dst.defence.gov.au (J.I.)

* Correspondence: kate.ponton@dst.defence.gov.au

\begin{abstract}
This paper reports on the development, method, and major findings from the Submarine Habitability Assessment Questionnaire (SUB-HAQ) undertaken as part of a lessons-learned review of the current RAN submarine platform. The questionnaire was completed by 167 Royal Australian Navy (RAN) Submariners and was developed to examine the perceived habitability of the main living and working areas. The results showed satisfaction with cleanliness, lighting, privacy of amenities, ventilation in certain areas, and location of amenities and facilities. The results also suggest dissatisfaction with aspects of the work areas (such as storage space for work materials, and space to conduct off-watch work), allocation of space and equipment for exercise, crowding, and ratio of crew to amenities. Best use of space on a submarine is an extraordinarily challenging design problem. However, it was concluded that significant benefit could be achieved through applying human systems integration methods early in the design of a future RAN platform. The importance of careful workforce planning and crewing analyses to prevent occurrences of overcrowding, lack of storage, and an unacceptable ratio of crew to amenities was observed. The findings from SUB-HAQ have led to a significant investment in evidence-based habitability design assurance by the RAN.
\end{abstract}

Keywords: habitability; shipbuilding; submarine; Navy; human systems integration; human factors

\section{Introduction}

Ship (surface ship) and boat (submarine) habitability can be a crucial factor in the successful conduct of both commercial operations and the sustainment of combat operations due to the impact that it has on personnel morale, safety, health and comfort, personnel effectiveness and productivity, recruitment and retention [1-3]. Yet it is also reported that there is a serious lack of exploration into the factors which affect satisfaction with shipboard life [4]. Whilst there have been some surveys conducted on US Navy Ships [4-8], there appears to be a complete absence of research conducted on whole-of-boat submarine habitability. This paper reports on research into maritime habitability, the development of a questionnaire tool to survey sailors' perceived habitability, and reports on the exploratory findings of the first research into whole-of-boat habitability on the Collins Class Submarine (CCSM).

\subsection{Shipboard Habitability}

Habitability is one of the human systems integration (HSI) considerations when acquiring or retrofitting government and commercial ships, offshore structures, and marine systems and equipment [9]. Shipboard habitability refers to "how hospitable the ship's conditions are-how well they satisfy the sailors' basic physical requirements to live and function, the level of comfort the conditions provide, and the adequacy of personal services supplied for the sailors" [4] (p. 116). From the above definition, it can be observed that there are two main components of habitability:

1. Biological habitability, which refers to the minimum standard of comfort and conditions that can be endured for an indefinite length of time without loss of effectiveness; 
2. Sociological habitability, which is based on the society that the crew is drawn from and how this compares with what is available to the crew on board [2] (pp. 1-4).

As such, for the crew to be effective and comfortable for the length of a deployment, the living and working spaces must provide for both the essentials of life as well as comforts in line with current standards of living [10].

\subsection{Combat Ship Habitability}

Research on combat ship habitability is generally lacking, particularly in regards to submarines. The majority of available research stems from habitability investigations in the United States Navy (USN), with the most recent whole-of-ship habitability being conducted in 2008 [4]. Research into combat ship habitability has outlined the habitability issues to include:

Poor berthing,

Lack of personal storage space,

Inadequate climate control,

Poorly designed bathrooms with poor fixtures,

Inadequate heads,

Inadequate/poorly designed mess,

Unreliable galley equipment,

Long mess lines, and

A shortage of fresh water [4,6-8].

Previous research has also found that a person's rank can affect their level of satisfaction [6], which may be explained by rank affecting allocated living spaces including the mess, cabins, heads, and showers.

It has been reported that an initial lack of attention to habitability can be due to a history of military conscription in some ship-building countries. This can result in a consistent level of manpower that reduces the need to focus on recruitment and retention. Subsequently, factors such as habitability are less important to building and sustaining the workforce [7]. Whilst warship design has been described as involving endless compromise, it is stated as essential that the overall wellbeing of the crew is not jeopardised [2].

\subsection{Habitability Influence on Operational Readiness and Crew Retention}

Vessel design that maximises the quality of life at sea can help sustain operational readiness, and improve retention $[1,2,4,6,7,11]$. The work environment in sea-going conditions can be complex and challenging, with a variety of environmental, work and social stressors that can affect the ability to maintain normal levels of alertness, performance, and physiological and psychological wellbeing [2,12]. Due to living and working on the one platform, respite from the environment is not always possible, allowing the stressors to degrade operational performance overtime and lead to a reduced willingness to stay in the Navy.

Research on USN ship habitability has indicated a strong relationship between dissatisfaction with habitability and dissatisfaction with shipboard life overall. In addition, $65 \%$ of first-term enlisted sailors reported that shipboard life decreased their desire to stay in the Navy [5].

In challenging and isolated environments such as long endurance maritime platforms, general issues or incidents which may seem innocuous ashore can interfere with performance and wellbeing on deployments [10].

\subsection{Key factors Affecting Habitability}

Appropriate habitability is dependent on a number of factors including the vessel's purpose, where it operates, the length of deployment, and the living and working conditions ashore [2]. The reference to living and working conditions ashore is pertinent when considering habitability, as improvements in standard of living over time are likely to change habitability expectations. 
As mentioned above, the appropriateness of the habitability is affected by the length of the deployment. However, there appear to be no specific rules or standards as to what level of habitability is required for a particular deployment length. Generally, it is believed that the longer the deployment is, the more important habitability is [10]. In addition, the confinement, isolation, and stress that can be characteristic of deployments creates a psychological need for more room and a sense of privacy. Therefore, the need for personal space becomes more important for longer deployments. In guidelines set out by the National Aeronautics and Space Administration (NASA), who also design for confined, isolated, and challenging work environments, the total required net habitable volume per crewmember and per total crew complement increases with deployment duration [13].

These guidelines have important implications for the Royal Australian Navy (RAN) when designing new submarines. The Collins Class Submarine (CCSM) has been described as having a severe lack of space and an almost total absence of privacy; it also travels great distances as a matter of routine [14], with a range of 11,500 nautical miles when surfaced and 400 nautical miles when dived [15] with a crew of 58 [16]. With the expectations that Australia's future submarine will have a greater range and longer patrol endurance [16] than the CCSM, habitability will be an important endurance and capability driver. Identifying the habitability issues with the current platform (CCSM) provides key information on where to focus human systems integration (HSI) resources to a new design. Whilst aspects of habitability have been addressed in a previous review [14], no comprehensive survey data collection has occurred before focusing on CCSM habitability. To better understand the habitability issues and opportunities with CCSM, Defence Science and Technology Group (DSTG) were tasked to gather the state of perceived habitability. To the knowledge of the authors, this is the first whole-of-boat habitability survey on a submarine published in the open literature.

\subsection{Habitability Questionnaires}

To gather the required data, a review of existing habitability questionnaires was conducted to determine whether an existing questionnaire could be used for data capture. Four main existing habitability questionnaires were identified: Navy Quality of Life (QOL) Survey [17]; The Habitability and Shipboard Climate Questionnaire [18]; Habitability Assessment Rating Scales [19]; and Habitability Issues Questionnaire [10].

These four questionnaires were not considered suitable to collect data on submarine habitability as they often focused on other platform types which cover habitability aspects not applicable to submarines, and/or were also focused on other constructs such as quality of life ashore. As no suitable questionnaire could be sourced, the authors developed a submarine specific questionnaire to gather the required data titled the Submarine Habitability Assessment Questionnaire (SUB-HAQ); see Appendix A. The aim of this questionnaire was to understand the aspects of habitability that are important to RAN submariners, where the main areas of dissatisfaction with current habitability were so they could be addressed in a future submarine, how habitability may affect retention, and how aspects such as rank may affected perceived habitability.

\section{Materials and Methods}

\subsection{Development of SUB-HAQ}

A list of all possible items was developed, taken from existing questionnaires, relevant literature, reports, relevant standards, and context-specific design drivers. Items from this list were then removed if they were duplicate questions, and/or if they are not relevant to the CCSM (e.g., questions such as access to and satisfaction with telephones, internet, snack bar, recreational lounges and hair dressers). This process of item selection and development was conducted to ensure questions relating to habitability in general were covered, as well as issues specific to the CCSM were addressed. When developing the additional items, reference was made to guidelines on question design and format $[20,21]$. 
The four main habitability surveys mentioned previously all utilise a Likert or other type of scale and/or free comment sections. This format was adopted for SUB-HAQ. Some items from existing questionnaires were adapted where required to suit the Likert format being used (e.g., adapting from a 7-point scale to a 5-point scale, strongly disagree-to strongly agree).

A shortlist of questions was developed which revolved around the topics: space/size and human factors engineering, environmental, number of facilities/crowdedness, location and access, privacy, cleanliness, fixtures/fittings/materials, social/leisure/exercise, utilities, and general. The items on these topics were grouped into the sections across the boat to provide meaningful areas to the participants. The sections of SUB-HAQ were: work area (17 items), mess area (space for meals and leisure, 13 items), cabins (19 items), heads (toilets, 8 items) and showers (11 items), social/leisure areas (5 items), utilities (6 items), and general (21 items). Effort was made to keep the number of questions to a minimum whilst attempting to elicit comprehensive information. To assist this effort, an open-ended question was presented at the end of each section to allow participants to go into detail about a question they may have agreed or disagreed with, and to expand on the specifics of their habitability issues. Demographic data was also collected.

\subsection{Piloting $S U B-H A Q$}

The SUB-HAQ was piloted on individuals from the intended population to test face and content validity, how well the questionnaire flowed, if questions were understood or skipped, and to ensure the instructions were adequate [21]. Some minor changes to the questionnaire structure and language used were made. Piloting was conducted on four currently serving RAN submariners. Time constraints did not allow for more comprehensive piloting which could have served to further refine the questionnaire.

Ethics approval was obtained via the DSTO low risk human research ethics protocol, number: MD 06-14.

\subsection{Participants}

The SUB-HAQ was administered as a cross-sectional design survey. Participants were sought from serving RAN submariners at HMAS Stirling (Western Australia) with the exception of trainees that had not yet been to sea. In total, 283 submariners were given the opportunity to complete the SUB-HAQ survey, and responses were received from 174 (response rate of 61\%, including 167 males, 4 females, and 3 unidentified).

\subsection{Materials}

Both paper-based and iPad-based questionnaires were used. However, iPads were the primary method of questionnaire administration, with paper-based questionnaires being given to participants who wanted to complete the questionnaire at a later time. It was noted during data analysis that there was a tendency for participants to elaborate further in the open-ended questions when using iPads compared with the paper questionnaire.

\subsection{Analysis Approaches}

Data from 7 participants were removed from analysis. The 1 participant had experience with submarines but was never a submariner, and 6 had answered the questionnaire based on the habitability of their current shore position and not in regards to a CCSM. Therefore, the total number of questionnaires used for analysis was 167.

When looking at the effects of rank on perceived habitability, some ranks were combined due to small sample sizes. Data from the Sub-Lieutenant rank $(n=1)$ was incorporated into the Lieutenant rank, and data from the Captain rank $(n=2)$ was incorporated into the Commander rank.

Responses on 14 Likert scale responses were reverse-coded, such that scores on all items reflected level of satisfaction from 1 (very dissatisfied) to 5 (very satisfied). 


\section{Qualitative Data}

In addition to responding to specific habitability questions, participants were also asked to answer open-ended qualitative questions. These questions provided an opportunity for participants to elaborate on any significant causes of distress or annoyance, and to indicate aspects of design that should be maintained in a new design. The NVivo 10 software package was used to organise and analyse these qualitative responses [22]. NVivo is used to scan text to find words and phrases, identifies frequency and clusters of words.

Prior to analysis, the researchers reviewed the responses together with a RAN reserve submariner who acted as a subject matter expert. Through this review, held over two days, the meaning of any ambiguous or unclear responses was clarified. For example, some responses would contain acronyms or refer to aspects of submarine life which the researchers were unfamiliar with.

The qualitative responses were then collated and edited to correct any spelling errors, as these would affect the accuracy of the later analyses. Commonly occurring words with the same meaning were also standardised to improve clarity of results. For example, references to 'storage' and 'stowage' were all changed to 'storage', and references to 'air conditioning', 'air cons' or 'AC' were all changed to 'AC'.

A word frequency analysis was conducted for each of the open-ended questions to identify the most commonly occurring issues in the respondents' answers. NVivo 10 was configured so that 'stemmed' words were counted together. For example, the words 'seats' 'seat', 'seated', and 'seating' would all be included in the count for 'seats'. It should be noted that by far the majority of responses reflected areas that needed improving. Therefore, the common words that are reported should be noted as aspects that the submariners were dissatisfied with. It is reported in the results where the frequency analysis aligned with the Likert responses.

\section{Results}

\subsection{Demographics}

Of the 167 participant questionnaires analysed, 4 were female and 163 were male. A total of 165 participants were employed in the Permanent Naval Force (PNF), with 1 in the Continuous Full-Time Service (CFTS), and 1 in the Active Navy Reserves (ANR). Participants were from varied job categories, which ensures that information is captured across the different CCSM work areas, with the exception being Medical and Stores, where there was only one participant in each category; see Table 1.

Table 1. Distribution of participant job categories.

\begin{tabular}{cc}
\hline Job Category & \% of Participants \\
\hline Maritime Warfare Officer & 10 \\
Acoustic Warfare Analyst & 20 \\
Communication Information Systems & 4 \\
Marine Engineer & 19 \\
Weapons Electrical Engineering & 25 \\
Electronic Warfare & 12 \\
Medical & 1 \\
Stores & 1 \\
Other & 8 \\
\hline
\end{tabular}

Table 2 presents the distribution of participants' ranks. The majority of participants were Junior Sailors (Seaman-Leading Seaman), followed by Senior Sailors (Petty OfficerWarrant Officer), and Officers (Sub Lieutenant-Captain). 
Table 2. Distribution of participant ranks.

\begin{tabular}{cc}
\hline Rank & \% of Participants \\
\hline Captain & 1 \\
Commander & 3 \\
Lieutenant Commander & 4 \\
Lieutenant & 8 \\
Sub Lieutenant & 1 \\
Warrant Officer & 4 \\
Chief Petty Officer & 10 \\
Petty Officer & 11 \\
Leading Seaman & 23 \\
Able Seaman & 34 \\
Seaman & 1 \\
\hline
\end{tabular}

The majority of participants had recent sea experience, which should result in reliable recollection of CCSM habitability; see Table 3.

Table 3. Time since last at sea on a Collins Class Submarine.

\begin{tabular}{cc}
\hline Time Since Last at Sea & \% of Participants \\
\hline Less than 1 year & 69 \\
1-3 years & 21 \\
3-5 years & 7 \\
5-10 years & 2 \\
10 years + & 1 \\
\hline
\end{tabular}

\subsection{Likert Item Responses}

Satisfaction ratings on each of the Likert scale questions were averaged across individuals to provide an overall satisfaction rating. To examine whether there were any overall themes that affected satisfaction and dissatisfaction with CCSM habitability, the highestand lowest-rated items are first presented, followed by a breakdown of responses by work and living areas. Figure 1 outlines the 20 most satisfying aspects (the highest average satisfaction ratings) and Figure 2 the dissatisfying aspects (the lowest average satisfaction responses) of CCSM habitability from the participants' responses.

The most satisfying aspects of perceived CCSM habitability concern aspects of lighting, location and privacy of facilities, and ventilation of non-work spaces concerning the showers, mess, heads, cabins and the general environment. As such, the highest-rated satisfied items related to areas outside of the work area. The most dissatisfying aspects relate to ability to exercise, ratio of amenities to crew, storage space and a feeling of crowdedness in relation to the work area, exercise/leisure spaces, cabins, general environment, heads, mess, and showers. Therefore, the highest dissatisfaction ratings were mixed between work and non-work areas.

Although some aspects of habitability, such as the showers, have both highly ranked satisfied and dissatisfied items; there are distinct differences between the specific issues. The elements that participants were satisfied with concern factors such as location and lighting. Whereas the elements they were dissatisfied with concern issues of crowding and ratio of personnel to amenities. 


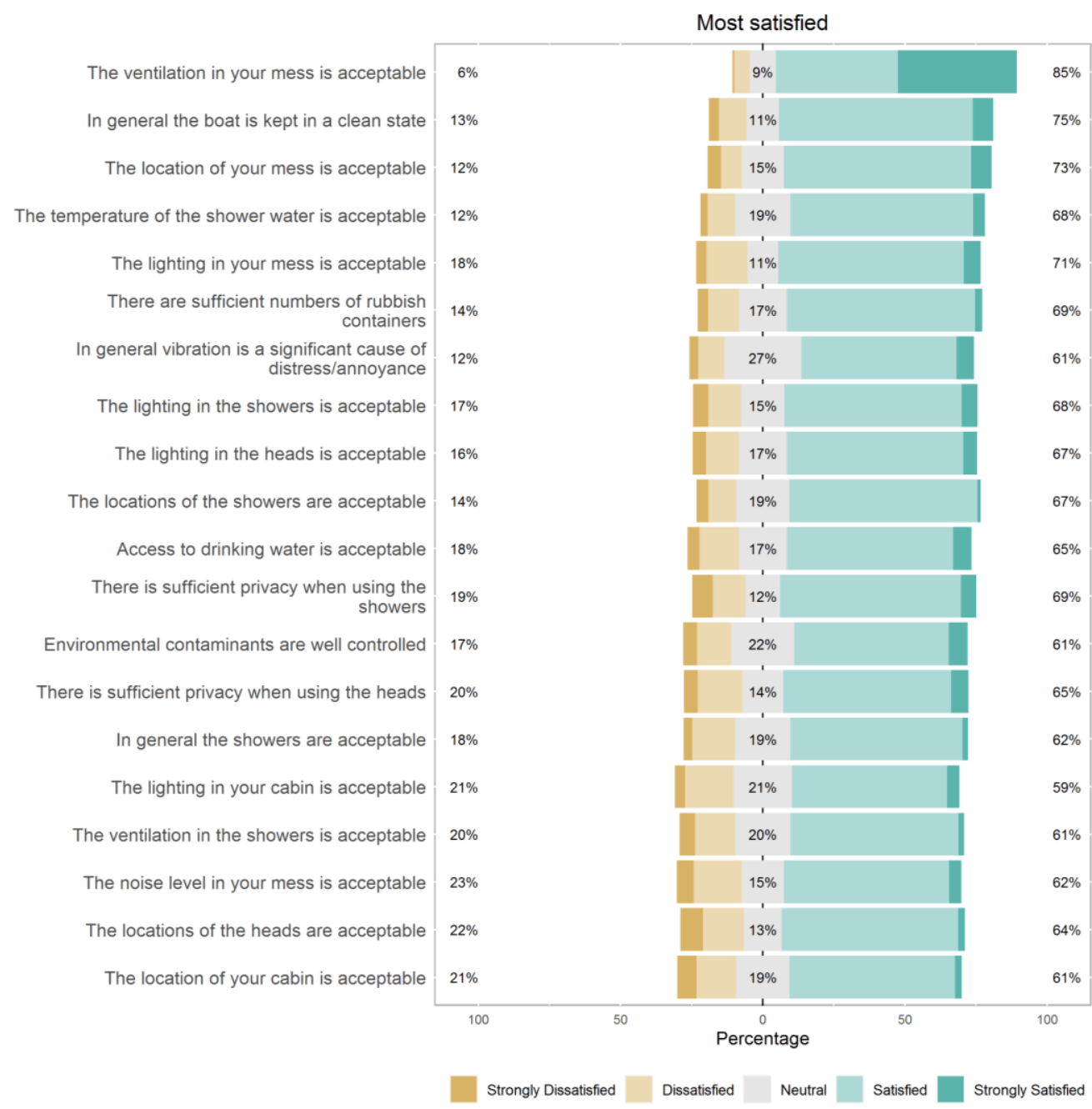

Figure 1. Items with the highest (top) mean satisfaction ratings. Note some items have been reverse coded to reflect low to high satisfaction. Values reflect (left to right) the percent of combined strongly dissatisfied and dissatisfied responses, percent of neutral responses, and percent of combined satisfied and strongly satisfied responses.

\subsection{Satisfaction Ratings by Area}

Average ratings were collated for each of the submarine areas: work area, mess area, cabins and general environment (which incorporates data from 'Social and Leisure Areas' and 'Utilities' due to the small number of questions in these sections). We first examined general satisfaction in these submarines areas by comparing the average rating for each area against a neutral rating of 3 . This revealed that participants had significant dissatisfaction with four of the six areas. Single-sample t-tests showed that ratings were significantly lower than neutral for work area $(\mathrm{M}=2.54, t(166)=9.83, p<0.01)$, cabin $(\mathrm{M}=2.76, t(166)=6.40$, $p<0.01)$, heads $(\mathrm{M}=2.83, t(166)=2.96, p=0.04)$ and general environment $(\mathrm{M}=2.86$, $t(166)=3.64, p<0.01)$. Participants were more satisfied than neutral with the showers $(\mathrm{M}=3.15, t(166)=2.80, p=0.06)$ and mess $(\mathrm{M}=3.13, t(166)=3.34, p=0.04)$.

The five most satisfying and dissatisfying aspects from each area as rated by all participants are shown in Figure 3. Due to the smaller number of questions relating to the heads and showers as compared to other sections, just the three highest-rated responses are presented for those areas. 


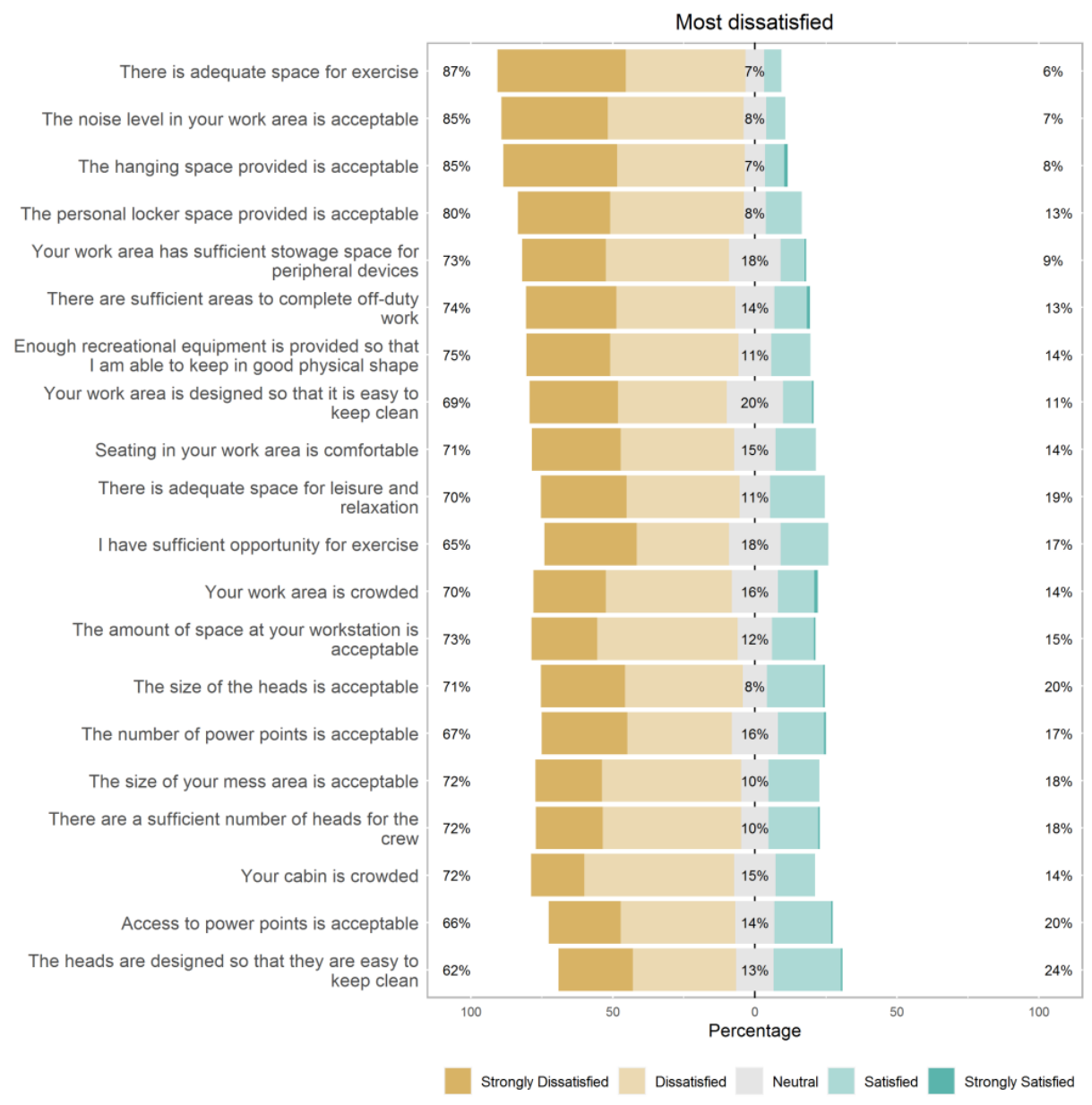

Figure 2. Items with the highest (top) mean dissatisfaction ratings. Note some items have been reverse coded to reflect low to high satisfaction. Values reflect (left to right) the percent of combined strongly dissatisfied and dissatisfied responses, percent of neutral responses, and percent of combined satisfied and strongly satisfied responses.

The main aspects of work area habitability that participants were most dissatisfied with were space, seating, and noise. Lighting and ventilation were the most satisfying aspects of work area habitability. All of the items in the work area besides those listed as the 5 most satisfied had dissatisfaction ratings greater than $50 \%$. Therefore, 12 of the 17 items in the work area had high levels of dissatisfaction. The most frequently reported themes in the qualitative data referred to space, seats, and room, which reiterated the main aspects that were dissatisfied with in the Likert items.

Overall, the aspects of the mess(s) that participants were most satisfied with included the ventilation, location, lighting, noise, and temperature. The primary aspects causing dissatisfaction were the size, layout, and comfort afforded. These issues causing dissatisfaction were repeated in the qualitative data in which the design of seating appears to be a primary factor negatively influencing ratings of layout and comfort.

The highest satisfaction rating concerning cabins regarded their lighting, location and privacy, although these questions were rated as being satisfactory by only a slight majority of participants. The top two issues causing most dissatisfaction concerned storage space for personal items and clothing. These were followed by issues concerning crowding, size of the bunk, and access to the bunk. These issues were reinforced by the qualitative data which presented bunks, space, and storage as the three most frequently reported issues. This is closely followed by issues with ventilation and frequent complaints regarding air conditioning in the cabins. Particular issues concerned the noise, location of vents and dispersion of air. 

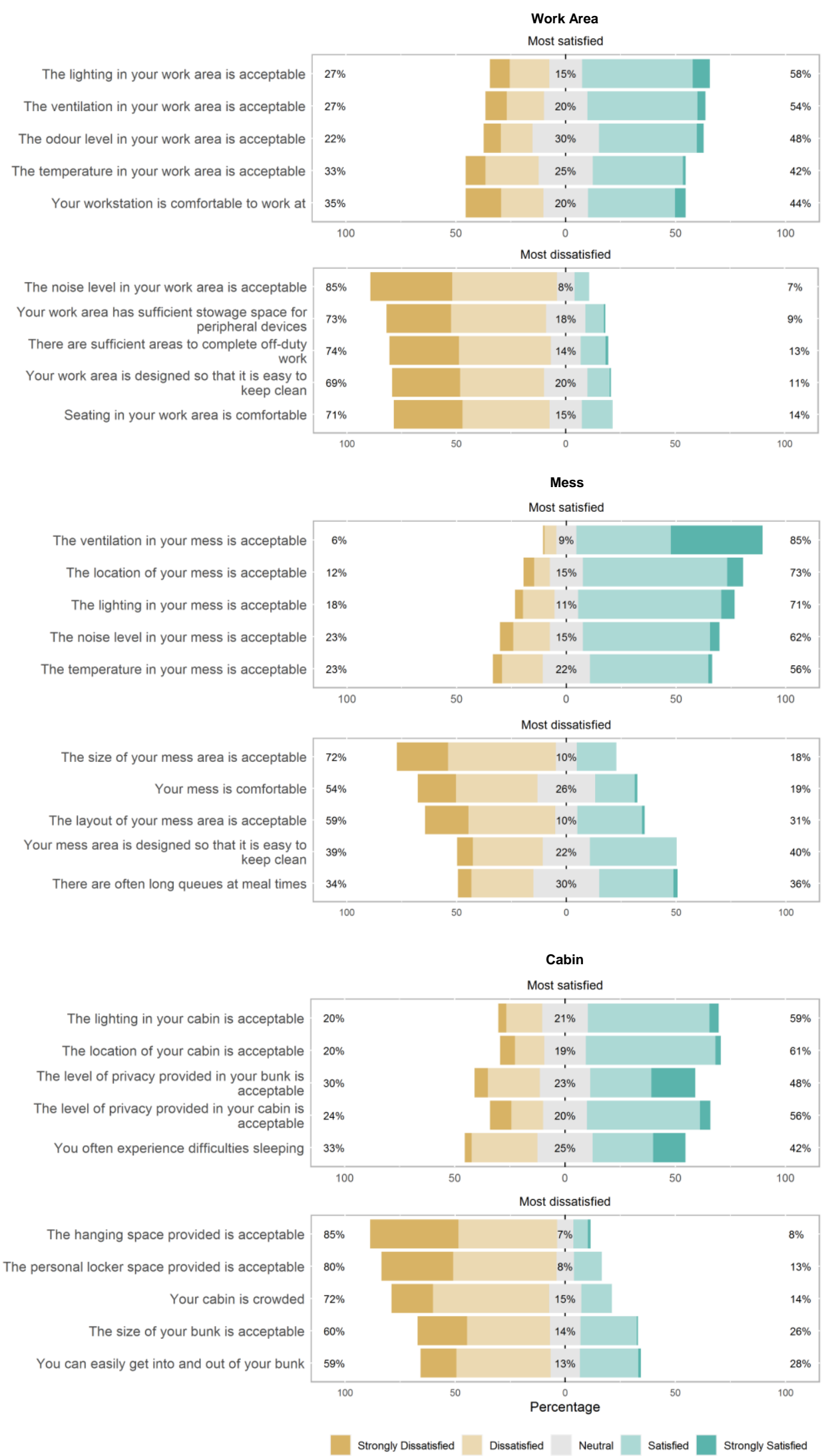

Figure 3. Cont. 


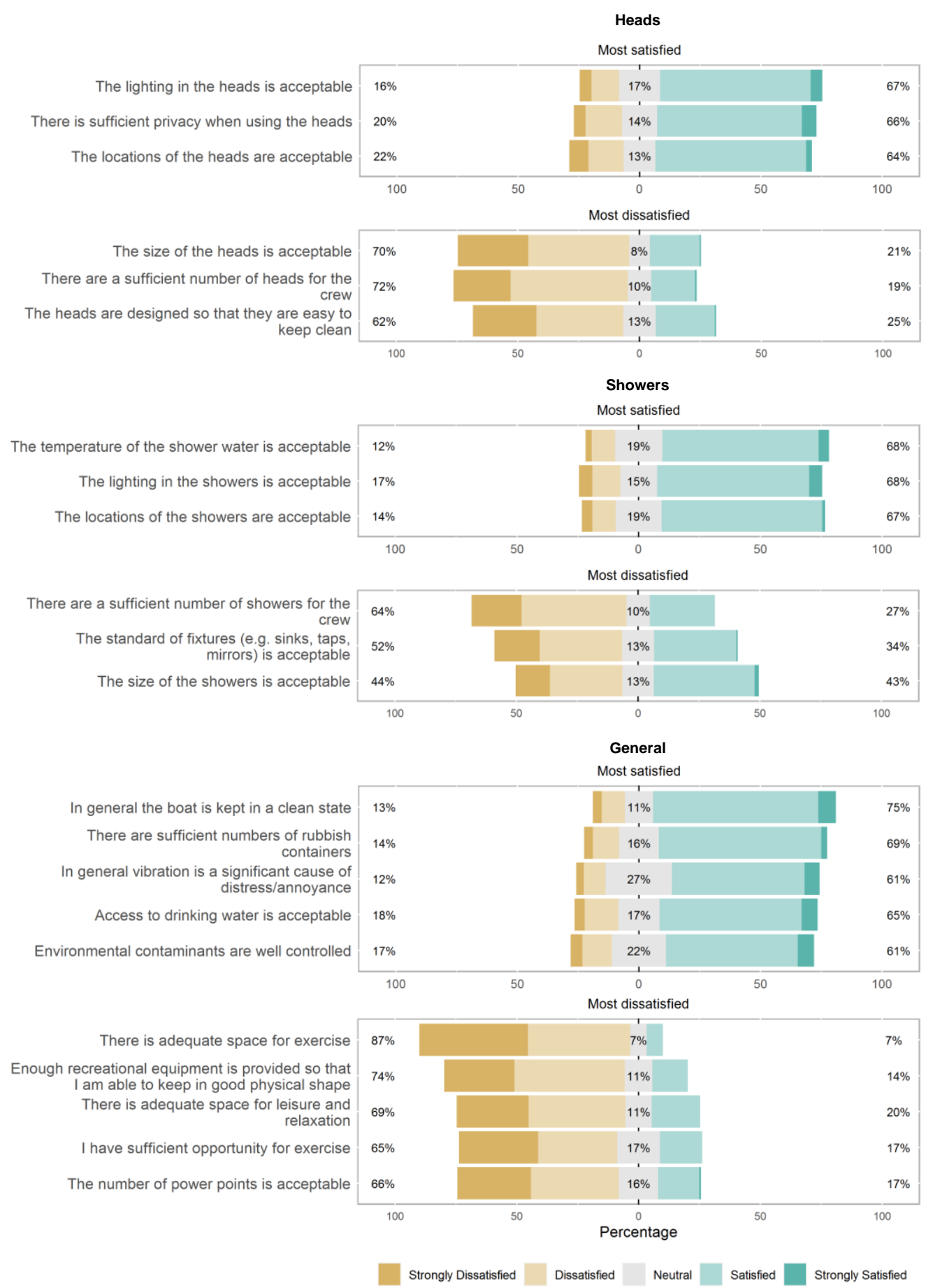

Figure 3. Items with the highest satisfaction and dissatisfaction ratings for each submarine area. Values reflect (left to right) the percent of combined strongly dissatisfied and dissatisfied responses, percent of neutral responses, and percent of combined satisfied and strongly satisfied responses.

The general habitable aspects the participants were most satisfied with were the cleanliness of the boat, numbers of rubbish containers, acceptable levels of vibration, access to drinking water, and control of environmental contaminants. In respect to some of these factors, however, there were a number of comments in the qualitative data that having a water fountain that could easily fill water bottles would be a positive improvement. Further, although respondents were generally satisfied with the number of rubbish containers on board, the qualitative data outlined a number of issues concerning the size of containers, 
space to store rubbish, disposal methods, and the smell generated. They also highlighted the need for separate laundry facilities so that submariners' clothes are not contaminated with fuel or other chemicals from materials used in the machinery and engineering spaces. The main habitability factors causing dissatisfaction regarded the lack of ability and equipment for exercise, and spaces for relaxation. Number of and access to power points was also a significant point of dissatisfaction, with both these factors being highlighted in the qualitative data as the most frequently reported issues.

Acceptable privacy and lighting were two common factors for the heads and showers that participants were highly satisfied with. The strongest factor that participants were dissatisfied with, and also common to both heads and showers, regards the number of amenities for the crew. In some cases, this is due to the space being used for storage. The size of the heads was also a strong source of dissatisfaction, as well as the difficulty in keeping both the heads and showers clean. This is reiterated in the qualitative data which draws a relationship between the size and design of amenities and the ability to keep them clean. Poor reliability of the amenities is also a key issue. As well as having a direct effect on living conditions and habitability, this also effectively reduces the already low number of amenities which further compounds this problem.

\subsection{Satisfaction in Main Areas by Rank Groups and Time in Submarine Force}

As submariners in different ranks can be exposed to different standards of living due to differences in the size, design, and ratio of crew to amenities, as well as the potential for different ranks to have different habitability expectations, results by rank were explored; see Figure 4 . The three rank categories were junior sailors $(N=98)$, senior sailors $(N=42)$ and officers $(N=27)$. To assess the impact of rank on satisfaction scores, one-way betweensubject ANOVAs were conducted on overall satisfaction scores, and scores for each of the main areas. Results revealed that rank had a significant effect on overall rating scores $(F(2$, $165)=3.60, p=0.30)$, and on scores on work area $(F(2,165)=5.85, p=0.04)$, mess $(F(2,165)$ $=7.44, p<0.01)$ and showers $(F(2,165)=3.09, p=0.48)$.

The results on overall satisfaction with different areas by rank indicates that Senior Sailors generally report the highest levels of dissatisfaction. Across the ranks, responses to most areas in general have overall low levels of satisfaction, with only the question 'In general the showers are acceptable' being rated as satisfactory by the majority of Junior Sailors, Senior Sailors, and Officers. Statistically, the comparison was significant for senior sailors compared with junior sailors on work area $\left(t(138)=3.30, p_{\text {corrected }}=0.14\right.$ ) and mess $\left(t(138)=3.53, p_{\text {corrected }}=0.07\right.$; all other $p_{\text {corrected }}>0.6$ when using a Holm-Bonferroni correction to the control family-wise error rate, [23]).

We also explored whether a submariner's time in the Submarine Force predicted their satisfaction ratings using linear regression. Time was coded as the minimum number of years completed in the Submarine Force as indicated in their demographics $(0,1,3,5$ or 10 years). Because time in the Submarine Force is related to rank, rank was added as a control variable in the regression model. Results showed a significant relationship for work area ratings only: longer time in the Submarine Force predicted more dissatisfaction, regardless of rank $(\beta=-0.3, t(166)=2.55, p=0.12)$, although note that this was not significant when corrected for multiple comparisons $\left(p_{\text {corrected }}=0.84\right.$ [23]), suggesting further data collection is required to determine whether this relationship is reliable. 


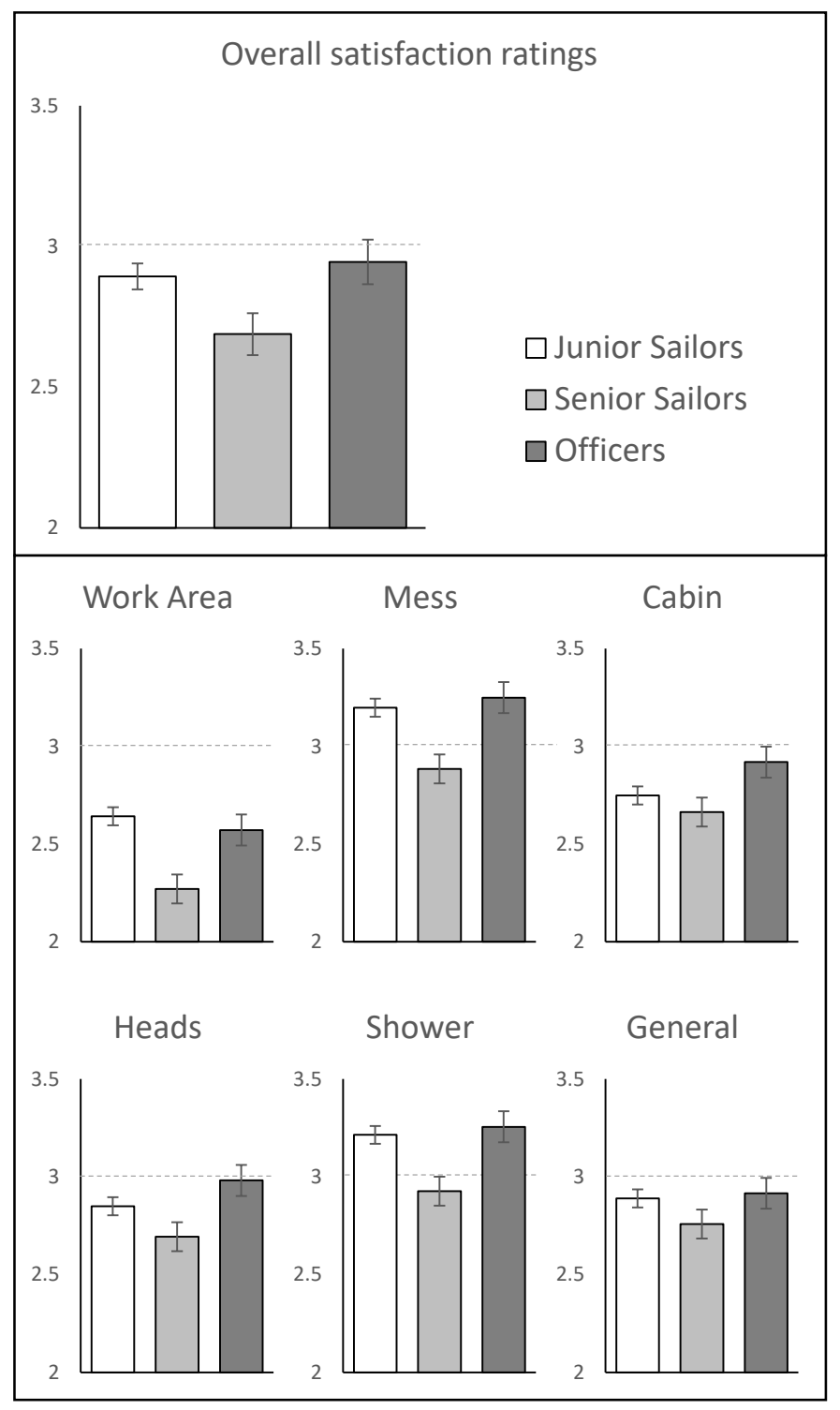

Figure 4. Mean rating scores for each rank group on overall ratings and each of the submarine areas. Ratings below the dashed line (neutral) indicate dissatisfaction, and scores above indicate satisfaction. Error bars show the standard error of the mean.

\section{Discussion}

In the free comment sections of the SUB-HAQ, submariners acknowledged and expect there to be certain hardships on a submarine compared to normal living conditions. However, results suggested high levels of dissatisfaction regarding factors that interfere with work effectiveness, basic living conditions (e.g., the number of heads), design of living and work spaces, and perceived impacts on personal health. Expanding on this, it is clear that certain elements affecting habitability could be substantially improved if considered and addressed early in the design process. For example, $59 \%$ of participants were dissatisfied with the layout of their mess. Further, $52 \%$ of participants were dissatisfied with the standard of fixtures in the showers. These issues may be addressed quite simply, with little impact on factors such as space, weight and power, through more careful design consideration and attention to user requirements.

Of particular interest was the level of dissatisfaction concerning the work area. It is sometimes reported that habitability is traded for operational requirements in design, and that designing a military platform should focus on operational readiness. The results 
of the SUB-HAQ indicate that these fundamental capability elements are also at risk when not considered in a structured, evidence-based, and methodical way in design. Habitability issues concerning the work area often related to stowage for peripheral devices, the amount of space at workstations, and a lack of space for off-duty work. Other strong themes generated in both Likert question and qualitative data were dissatisfaction with ergonomics, seating and console design. A significant relationship was found between time in the Submarine Force and dissatisfaction with the work area, which may indicate a wear and tear type effect of poor habitability on morale. Whilst submariners strive to do the job given the work environment, aspects of the work environment and work design can lead to high levels of dissatisfaction over time in perceived habitability.

Across many areas of the CCSM, issues relating to ergonomics and human factors engineering were apparent. Concerns regarding seating, space, and workstations were frequently reported for all work areas with more than $70 \%$ of participants being dissatisfied with these factors overall. Primary areas of dissatisfaction with the mess concerned its size, access, and comfort which all tie into human factors engineering. The cabins also had high levels of dissatisfaction with their size, and access to the bunks. As well as improving comfort and access, more attention to human factors engineering in the cabins could improve sleep and rest, which could positively impact crew fatigue and overall effectiveness.

Issues of crowding and the ratio of crew to amenities and facilities were another high point of dissatisfaction from the participants. This has likely been affected to some degree by the increased scheme of complement (SoC) on CCSMs. Although the increased SoC to $58 \mathrm{crew}$ is a positive and necessary measure to increase endurance and sustainability of the workforce [17], it may have negatively affected habitability. There were reports of spaces originally intended for recreation now being used for alternate purposes. For example, the space between the galley and the Junior Sailors' amenities was reported as initially for Senior Sailors to have their meals (with the mess intended purely for recreation). This space is now used for storage or for additional bunks. The Senior Sailors' mess is now used for meals, recreation, and as an additional workspace. As noted in the above comments, the increased SoC further compounds issues of storage, which was a major point raised that affects the cabins, work areas, and provision of amenities. For example, one of the two showers allocated for Junior Sailors is used for storage. Size of the heads and showers was also a point of dissatisfaction; and the lack of heads aft (no toilets in the back half of the CCSM) is a particular issue for those working in the machinery and engineering spaces, who may be unable to stand down during their on-watch work to use the toilets which are only located in the forward half of the boat.

Overall mean ratings by rank found that the Senior Sailors were more dissatisfied than Junior Sailors (significant difference) and Officers across all areas of the boat. This could be explained by Senior Sailors having fewer direct promotion opportunities and feeling more able to express themselves freely without impacts to their career. Potentially also being a Senior Sailor has given them the opportunity to see and experience the conditions afforded to Senior Sailors on other platforms which may contribute to a level of dissatisfaction with submarine habitability.

The advancement and portability of personal electronic devices may seem to be a primary contributor to the dissatisfaction with power points. However, there has also been an increased use of portable devices for work purposes. Therefore, the number and access to power points are issues in both work and recreational spaces.

Whilst these findings are specific to the CCSM, which is a diesel electric submarine (therefore, generally smaller than nuclear-powered submarines and, as such, more space constrained), the findings may be of use to other submarine forces who may be looking to address habitability. Indeed the findings from SUB-HAQ have led to a significant investment in evidence-based habitability design assurance by the RAN.

From the individual findings, high-level conclusions are presented below, which could have more widespread relevance to other Navies and commercial shipping sectors. 


\section{Conclusions}

From the data collected with the SUB-HAQ, four main recommendations were made:

Integration of habitability early in the design process: It is apparent that there are high levels of dissatisfaction with certain habitability factors on CCSMs that could have potentially been resolved if addressed earlier in the design process. Given the relationships identified between habitability and retention, performance, morale, wellbeing, and operational readiness, it is recommended that new submarine programs address habitability from the earliest phases of concept design onwards.

Workforce planning and crewing analyses: The responses suggest that, in part, due to an increased scheme of complement, issues of crowding, lack of storage, and ratio of crew to amenities has worsened. Poor reliability of certain amenities and equipment can further compound this problem. To prevent habitability and standards of living from being degraded, workforce planning and crewing analyses will need to be carefully conducted early in the project design phase. The addition of personnel onto a platform in which they were not originally accommodated can have severe impacts on habitability.

Exercise and fitness: The desire for submariners to maintain physical health and fitness was extremely clear from the data. The CCSM does not afford submariners adequate opportunity to exercise and maintain fitness which resulted in significant levels of dissatisfaction. To improve habitability, as well as promoting a multitude of physical and mental health benefits, it is recommended that new submarine designs carefully consider the provision of space and equipment for exercise.

Human factors engineering and ergonomics: To assist evaluations and design, it is recommended that habitability policy and guidance documents should be sourced and/or developed. They should reflect the intended type of platform, be tailored to its requirements, reflect the intended users, and be based on current living standards whilst also projecting potential future requirements. It is recommended that such documents also outline the human factors engineering and ergonomic guidelines of the work areas and work stations, cabins, the mess, heads and showers, and general passage through the boat. It is also recommended that human factors specialists be engaged during the design process to ensure appropriate application of relevant guidelines.

\section{Limitations}

As stated throughout this paper, the findings reported are perceived habitability. Future habitability investigations could benefit from observations at sea and the additional collection of objective data. For example, collection of participant anthropometric data could be linked to responses on space and sizing of the living and working areas; and objective assessments could be made on noise, lighting, and temperature.

The SUB-HAQ questionnaire could also benefit from further development and refinement. Although the SUB-HAQ was designed based on other habitability questionnaires, and was piloted checking for face and content validity, this is the first time this questionnaire has been administered and has not been tested for validity and reliability. A factor analysis would also be beneficial in identifying underlying constructs and potentially redundant Likert items.

It is also possible that there may be cultural biases in the responses-for example the participants were Australian submariners who live in a Mediterranean climate, which affords them the ability to exercise frequently in a variety of settings. Such circumstances are possibly why the desire to exercise was so high. The quality of the findings would have also benefited from increased participation of female respondents.

Author Contributions: Conceptualization, K.P. and D.P.; methodology, K.P. and D.P.; validation, K.P., and D.P. and; formal analysis, J.I., K.P. and D.P.; investigation, J.I., K.P. and D.P.; resources, J.I., K.P. and D.P.; data curation, J.I., K.P. and D.P.; writing-original draft preparation, K.P. and D.P.; writing-review and editing, K.P. and J.I. All authors have read and agreed to the published version of the manuscript. 
Funding: This research received no external funding.

Institutional Review Board Statement: This study was approved by the Defence Science and Technology Group Low Risk Ethics Protocol MD 06-14.

Informed Consent Statement: Informed consent was obtained from all subjects involved in the study.

Data Availability Statement: Data sharing is not applicable to this article due to its classification.

Acknowledgments: The authors would like to acknowledge the valued contribution of Sheena Care and Jemma Coleman (Land Division, DSTG) for preparing the SUB-HAQ into a digital survey and supplying the iPads used for administration. The authors are also extremely grateful to the RAN Submarine Force for their openness, professionalism and commitment in completing the SUB-HAQ, and to CMDR Brian Chase, WO Carl Larkin, and PO Justin Hill who assisted greatly as Navy Liaisons.

Conflicts of Interest: The authors declare no conflict of interest.

\section{Appendix A}

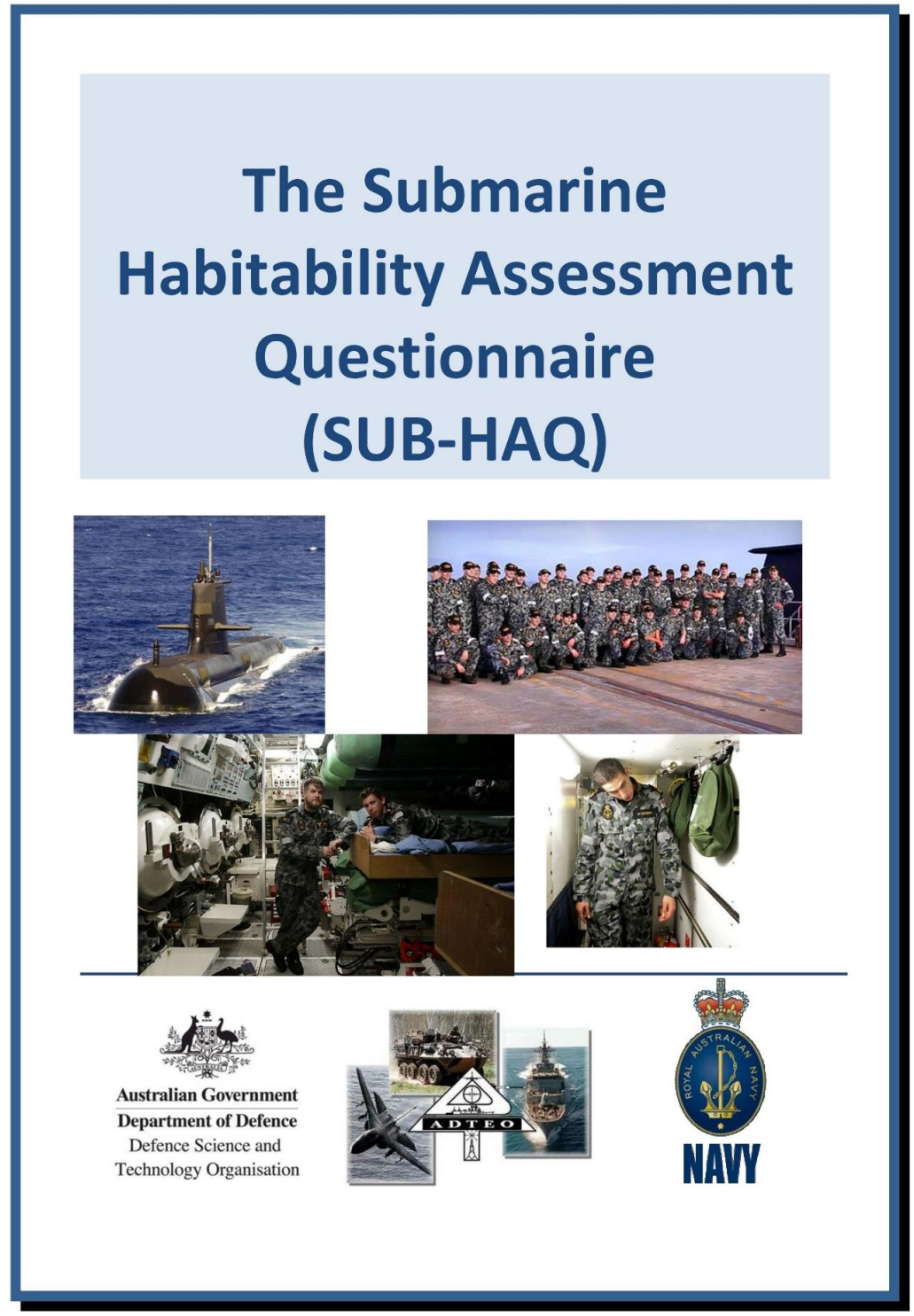

Figure A1. The Submarine Habitability Assessment Questionnaire. 


\section{Submarine Habitability Questionnaire (SUB-HAQ)}

The purpose of this questionnaire is to gather structured feedback on the habitability of the RAN Collins Class Submarine (CCSM) to inform design considerations for the future submarine platform. Please indicate your perceptions on how habitable your current platform is and write further comments where you would like to specify and extend on any issue you currently experience. The questionnaire should take approximately 15-20 minutes to complete. Many thanks for your assistance and cooperation.

\section{Demographics}

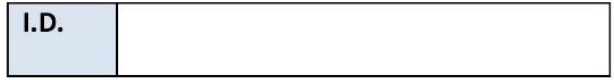

\begin{tabular}{|c|c|}
\hline Are you part of the: & $\begin{array}{l}\bigcirc \text { Permanent Naval Force } \\
\text { Continuous Full Time Service } \\
\text { Active Navy Reserves }\end{array}$ \\
\hline Time in RAN Submarine Force: & $\begin{array}{l}\text { Less than } 1 \text { year } \\
1-3 \text { years } \\
3-5 \text { years } \\
5-10 \text { years } \\
10 \text { years }+\end{array}$ \\
\hline Current rank: & $\begin{array}{ll}\text { OCAPT } & \bigcirc \text { WO } \\
\bigcirc \text { CMDR } & \bigcirc \text { CPO } \\
\bigcirc \text { LCDR } & \bigcirc \text { PO } \\
\bigcirc \text { LEUT } & \bigcirc \text { LS } \\
\text { SBLT } & \bigcirc \text { AB } \\
\text { ASLT } & \bigcirc \text { SMN } \\
\text { MIDN } & \end{array}$ \\
\hline Time in current rank: & $\begin{array}{l}\text { Less than } 1 \text { year } \\
1-3 \text { years } \\
3-5 \text { years } \\
5-10 \text { years } \\
10 \text { years }+\end{array}$ \\
\hline
\end{tabular}

Figure A2. The Submarine Habitability Assessment Questionnaire (continued). 


\begin{tabular}{|l|l|}
\hline Are you currently posted to sea or at shore? & $\bigcirc$ Sea \\
& $\bigcirc$ Shore \\
\hline Time since last at sea on a CCSM: & $\bigcirc$ Less than 1 year \\
& $\bigcirc 1-3$ years \\
& $\bigcirc 3$-5 years \\
& $\bigcirc 5-10$ years \\
& $\bigcirc 10$ years + \\
\hline
\end{tabular}

The following sections will ask you to indicate your level of agreement with several statements relating to various areas of the submarine on which you work, on a five-point scale ranging from "Strongly Disagree" to "Strongly Agree". Please mark your answer in the circles provided.

There will also be some open-ended questions asking you to provide extended answers. Please answer these questions as fully as you are able. If you require extra space, please complete your answers on the blank sheets provided at the end of the questionnaire, clearly indicating which question you are answering.

Figure A3. The Submarine Habitability Assessment Questionnaire (continued). 


\section{Work Area}

"Work Area" refers to the location in the CCSM in which you primarily complete your on-duty tasks.

\section{Your work area is:}

\begin{tabular}{|c|c|c|c|c|c|c|}
\hline & 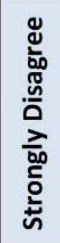 & 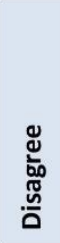 & $\begin{array}{l}\bar{\pi} \\
\bar{T} \\
\text { z }\end{array}$ & 迹 & 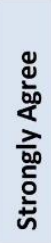 & $\overleftarrow{s}$ \\
\hline The amount of space in your work area is acceptable & 0 & O & O & O & 0 & O \\
\hline The amount of space at your workstation is acceptable & 0 & 0 & 0 & 0 & $\bigcirc$ & O \\
\hline There are sufficient areas to complete off-duty work & 0 & 0 & $\bigcirc$ & $\bigcirc$ & $\bigcirc$ & $\mathrm{O}$ \\
\hline Seating in your work area is comfortable & 0 & 0 & 0 & 0 & 0 & 0 \\
\hline Your work area is designed so that it is easy to keep clean & 0 & 0 & 0 & 0 & 0 & 0 \\
\hline $\begin{array}{l}\text { Your work area has sufficient stowage spaces for Classified } \\
\text { material }\end{array}$ & $\bigcirc$ & $\bigcirc$ & $\bigcirc$ & $\bigcirc$ & $\bigcirc$ & O \\
\hline $\begin{array}{l}\text { Your work area has sufficient stowage spaces for Unclassified } \\
\text { material }\end{array}$ & $\bigcirc$ & $\bigcirc$ & $\bigcirc$ & $\bigcirc$ & $\bigcirc$ & O \\
\hline $\begin{array}{l}\text { Your work area has sufficient stowage space for peripheral } \\
\text { devices (e.g. printers, shredders, laptops) }\end{array}$ & $\bigcirc$ & 0 & $\bigcirc$ & $\bigcirc$ & $\bigcirc$ & O \\
\hline Your workstation is comfortable to work at & $\bigcirc$ & O & O & 0 & 0 & O \\
\hline The lighting in your work area is acceptable & 0 & 0 & O & $\mathrm{O}$ & 0 & O \\
\hline The noise level in your work area is acceptable & O & 0 & O & 0 & O & O \\
\hline The temperature in your work area is acceptable & 0 & $\bigcirc$ & $\bigcirc$ & $\bigcirc$ & 0 & $\bigcirc$ \\
\hline The odour level in your work area is acceptable & 0 & 0 & $\bigcirc$ & 0 & $\bigcirc$ & 0 \\
\hline The ventilation in your work area is acceptable & 0 & 0 & 0 & 0 & 0 & 0 \\
\hline Your work area is crowded & 0 & 0 & 0 & 0 & 0 & 0 \\
\hline The layout of your work area is acceptable & 0 & 0 & 0 & 0 & 0 & 0 \\
\hline In general your work area is acceptable & 0 & 0 & O & 0 & $\bigcirc$ & 0 \\
\hline
\end{tabular}

Figure A4. The Submarine Habitability Assessment Questionnaire (continued). 
Please elaborate on any significant habitability issues in your work area as identified above, or any others not included. Keep in mind any changes you would like to see in future platforms.

Figure A5. The Submarine Habitability Assessment Questionnaire (continued). 


\begin{tabular}{|l|l|l|l|l|l|l|}
\hline & & & & & \\
\hline
\end{tabular}

Figure A6. The Submarine Habitability Assessment Questionnaire (continued). 
Please elaborate on any significant habitability issues with the mess area as identified above, or any others not included. Keep in mind any changes you would like to see in future platforms.

\section{Catering department only:}

Please elaborate on any significant habitability issues with the galley area as identified above, or any others not included. Keep in mind any changes you would like to see in future platforms.

Please describe a system for refrigerated stowage that you would want for extended periods at sea.

Figure A7. The Submarine Habitability Assessment Questionnaire (continued). 


\begin{tabular}{|c|c|c|c|c|c|c|}
\hline a & 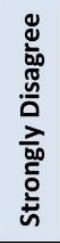 & 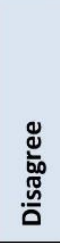 & 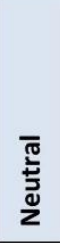 & 巡 & 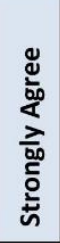 & $\frac{\nwarrow}{z}$ \\
\hline The size of your cabin is acceptable & O & O & $\bigcirc$ & 0 & O & $\bigcirc$ \\
\hline The size of your bunk is acceptable & 0 & 0 & 0 & $\bigcirc$ & $\bigcirc$ & 0 \\
\hline The location of your cabin is acceptable & 0 & 0 & 0 & $\bigcirc$ & $\bigcirc$ & $\bigcirc$ \\
\hline You can easily get into and out of your bunk & O & O & O & $\bigcirc$ & O & $\bigcirc$ \\
\hline Your bunk is comfortable & 0 & 0 & 0 & O & O & $\bigcirc$ \\
\hline Your cabin is crowded & O & O & 0 & $\bigcirc$ & O & $\bigcirc$ \\
\hline The hanging space provided is acceptable & $\bigcirc$ & $\bigcirc$ & $\bigcirc$ & $\bigcirc$ & $\bigcirc$ & $\bigcirc$ \\
\hline The personal locker space provided is acceptable & 0 & $\bigcirc$ & 0 & $\bigcirc$ & $\bigcirc$ & 0 \\
\hline The level of privacy provided in your cabin is acceptable & 0 & O & 0 & $\bigcirc$ & $\bigcirc$ & 0 \\
\hline The level of privacy provided in your bunk is acceptable & 0 & 0 & 0 & 0 & $\bigcirc$ & 0 \\
\hline You often experience difficulties sleeping & 0 & 0 & 0 & $\bigcirc$ & $\bigcirc$ & $\bigcirc$ \\
\hline The mattresses, pillows and bed linen are acceptable & 0 & 0 & 0 & O & O & 0 \\
\hline The lighting in your cabin is acceptable & $\bigcirc$ & $\bigcirc$ & O & $\bigcirc$ & $\bigcirc$ & $\bigcirc$ \\
\hline The noise level in your cabin is acceptable & $\bigcirc$ & $\bigcirc$ & O & $\bigcirc$ & $\bigcirc$ & $\mathrm{O}$ \\
\hline The temperature in your cabin is acceptable & O & $\bigcirc$ & $\bigcirc$ & $\bigcirc$ & $\bigcirc$ & 0 \\
\hline The odour level in your cabin is acceptable & 0 & 0 & 0 & $\bigcirc$ & $\bigcirc$ & 0 \\
\hline The ventilation in your cabin is acceptable & 0 & 0 & 0 & 0 & 0 & 0 \\
\hline Your accommodation is designed so that it is easy to keep clean & 0 & 0 & 0 & 0 & 0 & 0 \\
\hline In general your cabin is acceptable & 0 & 0 & 0 & 0 & 0 & 0 \\
\hline
\end{tabular}

Including yourself, how many people does your cabin accommodate?

Figure A8. The Submarine Habitability Assessment Questionnaire (continued). 
Please elaborate on any significant habitability issues in your cabin as identified above, or any others not included. Keep in mind any changes you would like to see in future platforms.

Figure A9. The Submarine Habitability Assessment Questionnaire (continued). 


\section{Heads \& Showers}

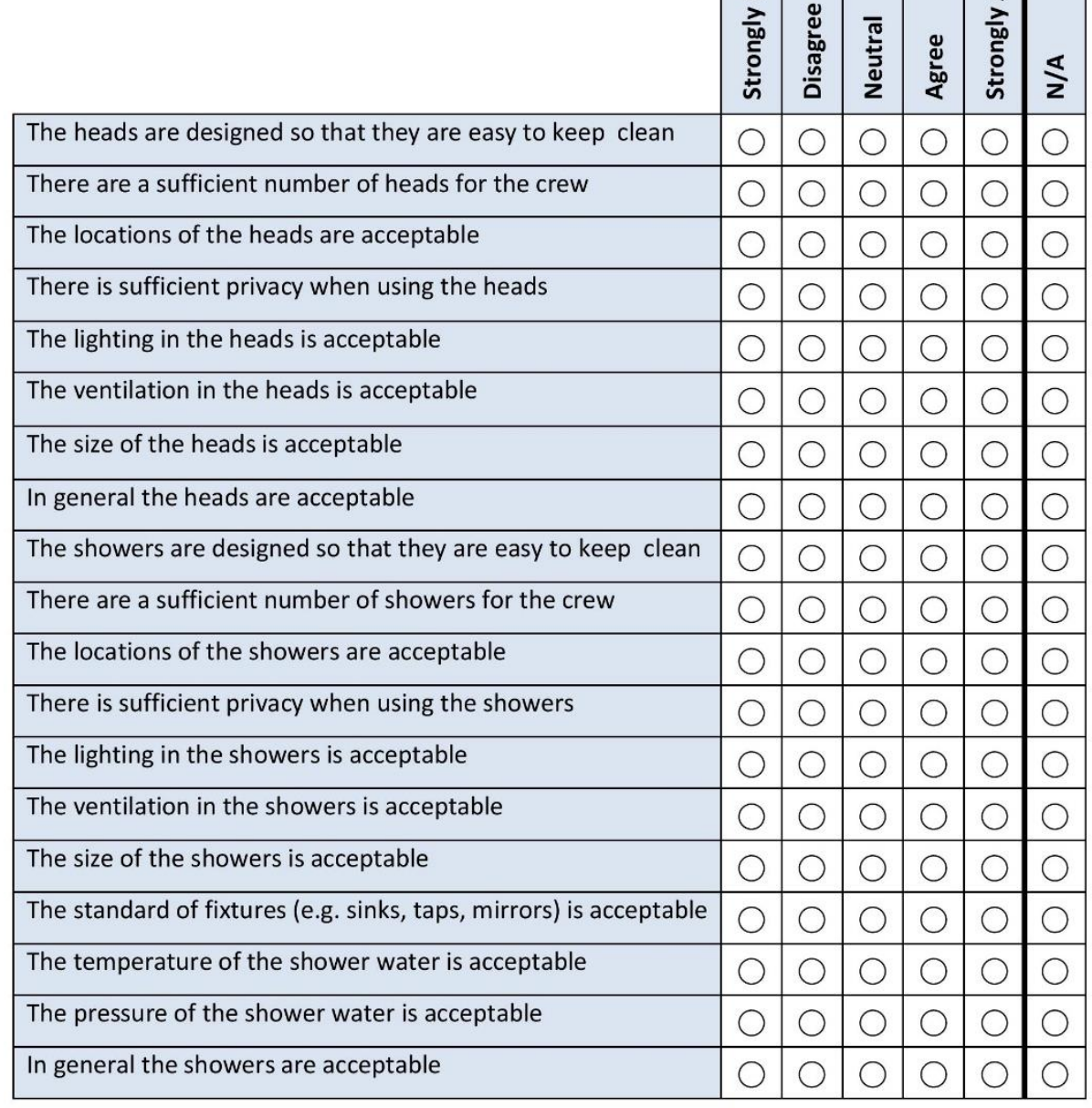

Figure A10. The Submarine Habitability Assessment Questionnaire (continued). 
Please elaborate on any significant habitability issues with the heads and/or showers as identified above, or any others not included. Keep in mind any changes you would like to see in future platforms.

Figure A11. The Submarine Habitability Assessment Questionnaire (continued). 


\section{Social/Leisure} Areas

\begin{tabular}{|c|c|c|c|c|c|}
\hline There is adequate space for exercise & $\bigcirc$ & & $\bigcirc$ & & O \\
\hline There is adequate space for leisure and relaxation & & & & & \\
\hline I have sufficient opportunity for exercise & & & & & \\
\hline $\begin{array}{l}\text { Enough recreational equipment is provided so that I am able to } \\
\text { keep in good physical shape }\end{array}$ & & & & & \\
\hline $\begin{array}{l}\text { The selection of leisure materials (e.g. books, games, movies, } \\
\text { music) provided is acceptable }\end{array}$ & & & & & \\
\hline
\end{tabular}

Please elaborate on any significant habitability issues with the social/leisure areas as identified above, or any others not included. Keep in mind any changes you would like to see in future platforms.

Figure A12. The Submarine Habitability Assessment Questionnaire (continued). 


\section{Utilities}

\begin{tabular}{|c|c|c|c|c|c|c|}
\hline & 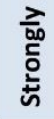 & 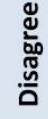 & 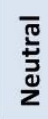 & 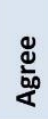 & 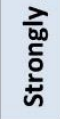 & $\frac{\varangle}{z}$ \\
\hline The number of power points is acceptable & $\bigcirc$ & $\mathrm{O}$ & O & O & O & $\bigcirc$ \\
\hline Access to power points is acceptable & $\bigcirc$ & O & $\bigcirc$ & $\bigcirc$ & $\bigcirc$ & $\bigcirc$ \\
\hline Access to drinking water is acceptable & $\bigcirc$ & $\bigcirc$ & O & $\bigcirc$ & $\mathrm{O}$ & $\bigcirc$ \\
\hline There are sufficient numbers of rubbish containers & $\bigcirc$ & $\bigcirc$ & O & $\bigcirc$ & O & $\bigcirc$ \\
\hline The rubbish containers have sufficient capacity & O & $\bigcirc$ & O & O & O & $\bigcirc$ \\
\hline Laundry facilities are acceptable & $\bigcirc$ & $\bigcirc$ & $\bigcirc$ & $\bigcirc$ & $\bigcirc$ & $\bigcirc$ \\
\hline
\end{tabular}

Please elaborate on any significant habitability issues with the shipboard utilities as identified above, or any others not included. Keep in mind any changes you would like to see in future platforms.

Figure A13. The Submarine Habitability Assessment Questionnaire (continued). 


\section{General}

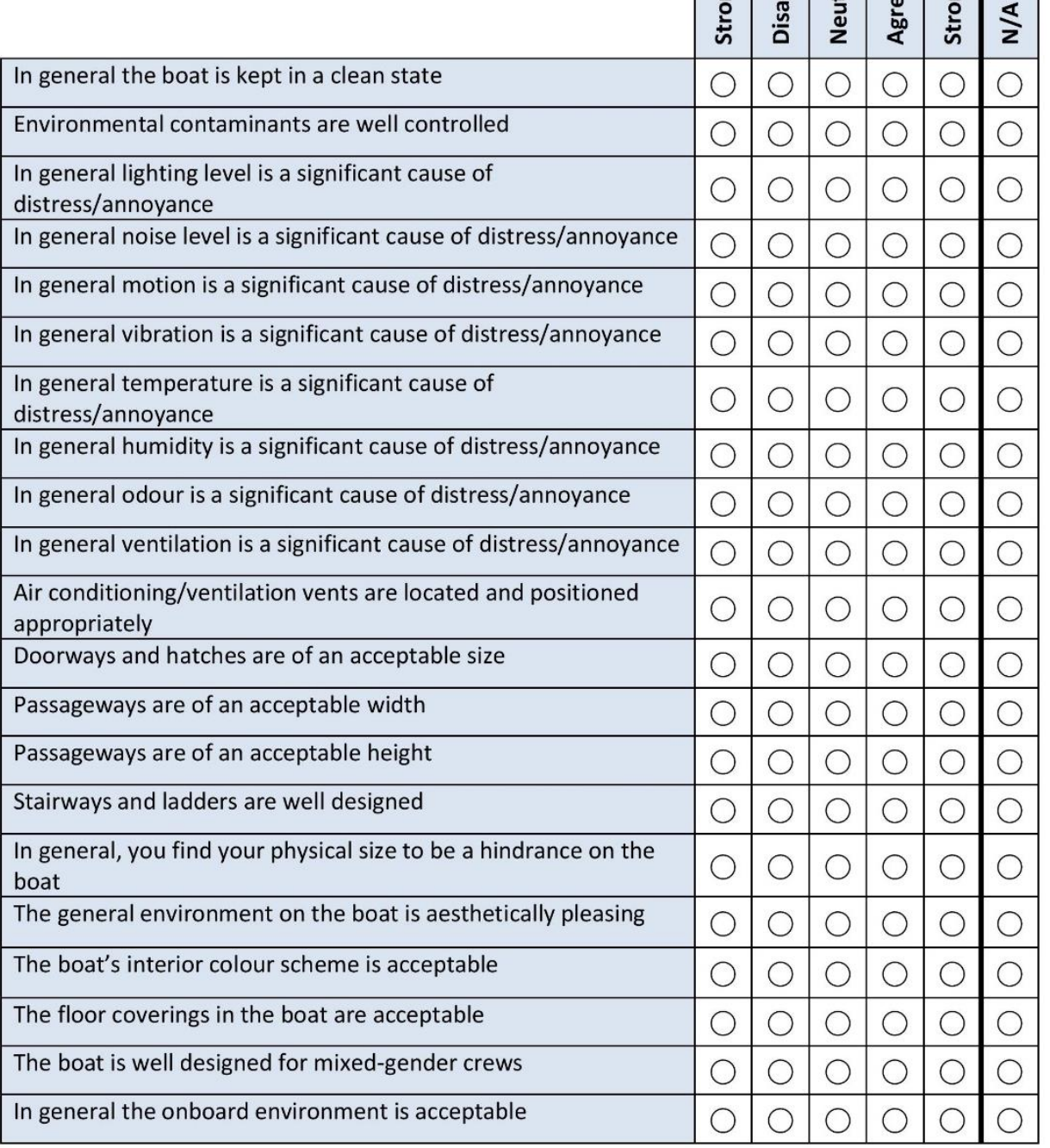

Figure A14. The Submarine Habitability Assessment Questionnaire (continued). 
Please elaborate on any significant causes of distress/annoyance as identified above, or any others not included. Keep in mind any changes you would like to see in future platforms.

Figure A15. The Submarine Habitability Assessment Questionnaire (continued). 


\section{Thank you for taking the time to completing this survey!}

If you have any other comments or advice on how to improve onboard habitability that you weren't able to express elsewhere, please share them below. Please include any suggestions for changes you would like to see in future platforms.

Figure A16. The Submarine Habitability Assessment Questionnaire (continued). 


\section{References}

1. Department of the Navy. OPNAV Instruction 9640.1B: Shipboard Habitability Program; Department of the Navy: Washington, DC, USA, 2012.

2. NATO. Guidelines for Shipboard Habitability Requirements for Combatant Surface Ships (ANEP-24); Allied Naval Engineering Publication: Brussels, Belgium, 1993.

3. American Bureau of Shipping. Guide for Crew Habitability on Ships; American Bureau of Shipping: Houston, TX, USA, 2012.

4. Wilcove, G.L.; Schwerin, J.M. Shipboard habitability in the US Navy. Mil. Psychol. 2008, 20, 18. [CrossRef]

5. Wilcove, G.L.; Schultz, R.A.; Patrissi, G.A. 2006 Navy quality of life survey. Navy Pers. Res. Stud. Technol. Div. Bur. Nav. Pers. 2007, NPRST-AB-07-6, 1-76.

6. Meere, E.P.; Grieco, L. Ship habitability: Preparing for the 21st century. Nav. Eng. J. 1997, 109, 21-27. [CrossRef]

7. Stephan, R.A. The Effects of Shipboard Living Conditions on First-Term Retention Rates and a Model for the Allocation of Funds among Habitability Improvements; Institute of Naval Studies Research Contribution: Washington, DC, USA, 1971.

8. Matsangas, P.; Shattuck, N.L. Habitability in berthing compartments and well-being of sailors working on U.S. navy surface ships. Hum. Factors 2020, 0018720820906050, published online. [CrossRef] [PubMed]

9. ASTM. F1337-10 Standard Practice for Human Systems Integration Program Requirements for Ships and Marine Systems, Equipment and Facilities; ASTM International: West Conshohocken, PA, USA, 2010.

10. Mount, F.E. Habitability: An Evaluation; National Aeronautics and Space Administration: Washington, DC, USA, 2002.

11. Wilcove, G.L.; Schwerin, M.J.; Wolosin, D.G. An exploratory model of quality of life in the US Navy. Mil. Psychol. 2003, 15, 19. [CrossRef]

12. Comperatore, C.A.; Rivera, P.K.; Kingsley, L. Enduring the shipboard stressor complex: A systems approach. Aviat. Space Environ. Med. 2005, 76 (Suppl. 6), B108-B118. [PubMed]

13. National Aeronautics and Space Administration. Human Integration Design Handbook (HIDH); National Aeronautics and Space Administration: Washington, DC, USA, 2010.

14. Moffitt, R. Navy's Response to the Submarine Workforce Sustainability Review; Department of Defence; Royal Australian Navy: Canberra, Australia, 2009; p. 160.

15. Royal Australian Navy. HMAS Collins. Available online: https:/ /www.navy.gov.au/hmas-collins (accessed on 28 December 2020).

16. Australian Government. Defending Australia in the Asia Pacfic Century: Force 2030; Defence White Paper; Australian Government: Canberra, Australia, 2009.

17. Wilcove, G.L. Results of the Navy Quality of Life Survey; Navy Personnel Research, Studies, and Technology: Millington, TN, USA, 2005.

18. LaRocco, J.M.; Gunderson, E.K.; Dean, L.M. Organizational and Environmental Factors in Health and Personnel Effectiveness: Data Collection Methods, Test Instruments and Criterion Variables; Naval Health Research Center: Washington, DC, USA, 1974.

19. Righter, C.E.; Nowlis, D.P.; Dunn, V.B.; Belton, N.J.; Wortz, E.C. Habitability Guidelines and Criteria; National Aeronautics and Space Administration: Washington, DC, USA, 1971.

20. Kaplan, R.M.; Saccuzzo, D.P. Psychological Testing, Principles, Applications, and Issues, 5th ed.; Nelson Education: Wadsworth, OH, USA, 2001.

21. Walter, M. (Ed.) Social Research Methods, 4th ed.; Oxford University Press: South Melbourne, Australia, 2019.

22. QSR International, Qualitative Data Analysis Software. NVivo Software 10. 2015. Available online: https://www.qsrinternational. $\mathrm{com} /$ nvivo-qualitative-data-analysis-software/home (accessed on 1 December 2020).

23. Holm, S. A simple sequentially rejective multiple test procedure. Scand. J. Stat. 1979, 6, 65-70. 